\title{
Identification of sex hormone binding globulin-interacting proteins in the brain using phage display screening
}

\author{
M. GNANASEKAR ${ }^{1}$, F.G. SULEMAN ${ }^{2}$, K. RAMASWAMY ${ }^{1}$ and J.D. CALDWELL ${ }^{3}$ \\ ${ }^{1}$ Department of Biomedical Sciences, University of Illinois College of Medicine, \\ 1601 Parkview Avenue, Rockford, IL 61 107; ${ }^{2}$ Thermo Fisher Scientific, 3747 N. Meridian Road, \\ Rockford, IL 61105; ${ }^{3}$ Department of Pharmacology, Lake Erie College of Osteopathic Medicine, \\ 1858 West Grandview Boulevard, Erie, PA 16509, USA
}

Received April 16, 2009; Accepted June 2, 2009

DOI: 10.3892/ijmm_00000248

\begin{abstract}
The present study reports the identification of human sex hormone binding globulin (SHBG)-interacting proteins in the brain using a phage display-based screening technology. Phage display is a system in which a foreign protein is displayed on the surface of a bacteriophage as a fusion protein with one of the coat proteins of the bacteriophage. T7 phage clones expressing normal human brain proteins (human normal brain phage-display cDNA expression library) were screened using SHBG as bait. The bound phage clones were then identified by DNA sequencing and by BLAST search analysis. Of the twenty binding proteins analyzed, three were found to be membrane-associated proteins: synaptosomal associated protein 25 (SNAP25), Thy-1 cell surface antigen and zonadhesin. Further studies will determine if the interactions of SHBG with these proteins have any role in the internalization and cell signaling events or whether they contribute to steroid delivery to specific cells.
\end{abstract}

\section{Introduction}

Examining the roles of steroid binding globulins as active participants in steroid actions has received attention recently. One reason is that there are membrane-associated receptors for binding globulins. Hryb et al (1) showed that sex hormone binding globulin (SHBG) binds with high affinity to a specific membrane receptor in prostate stromal and epithelial cells.

Correspondence to: Dr Munirathinam Gnanasekar, Department of Biomedical Sciences, University of Illinois College of Medicine, 1601 Parkview Avenue, Rockford, IL 61107, USA

E-mail:mgnanas@uic.edu

Dr Jack D. Caldwell, Department of Pharmacology, Lake Erie College of Osteopathic Medicine, 1858 West Grandview Boulevard, Erie, PA 16509, USA

E-mail: jcaldwell@lecom.edu

Key words: sex hormone binding globulin, brain, phage display, zonadhesin, synaptosomal associated protein 25
Nakhla et al $(2,3)$ demonstrated that SHBG binds to a receptor or receptor complex which then results in increases of intracellular cAMP. Studies by Rosner and colleagues $(3,4)$ suggest that the putative SHBG receptor is a $\mathrm{G}$ protein-coupled receptor or functionally linked to one. In these studies (1) a $167-\mathrm{kDa}$ protein was solubilized from membranes of human prostate glands and its binding activity to SHBG was demonstrated using ${ }^{125}$ I-SHBG. Other studies $(5,6)$ also suggested that there are membrane-associated receptors for SHBG in the uterus. These membrane-associated receptors may be important for internalization of SHBG, which was observed in many tissues (7-14) including the brain (15). The Nykjaer and Willnow laboratory demonstrated that a membrane-associated protein called megalin, a $600-\mathrm{kDa}$ member of the LDL receptor gene family, is capable of binding to and facilitating the internalization of both SHBG and its bound steroid (16). It is the protein that the same laboratory previously suggested was involved in the uptake of other steroids and demonstrated that it belonged to a larger class of proteins responsible for the uptake of a broad range of lipophilic molecules (17). Megalin is important in steroid effects. This group demonstrated that without megalin, mice showed a delayed onset of puberty (16). The same laboratory demonstrated the importance of binding globulins in mediating the effects of steroids. Mice lacking a corticosteroid-binding globulin, another steroid-binding globulin found in the brain $(18,19)$, had more free steroids in the blood but showed fewer physiological responses to them, suggesting that the presence of this binding globulin was necessary in order to see the effects of corticosteroids (20).

The first indication that there were SHBG receptors in the brain was when SHBG facilitated female sexual receptivity (21) except when coupled to dihydrotestosterone (22). Our laboratory and others also found that SHBG is produced in the brain, where it is often co-localized with the neuropeptides oxytocin and vasopressin (23-25). Since both SHBG and oxytocin are often found together in synaptic vesicles in axonal varicosities, we concluded that SHBG is likely released into the brain. This suggests the existence of receptors for this released SHBG. We also presented indirect evidence of such SHBG receptors in the hypothalamus (26). After binding to membraneassociated receptors, it is possible that SHBG, its associated steroid, and the SHBG receptor are all internalized into brain cells. Caldwell et al (15) demonstrated uptake of SHBG in vivo 


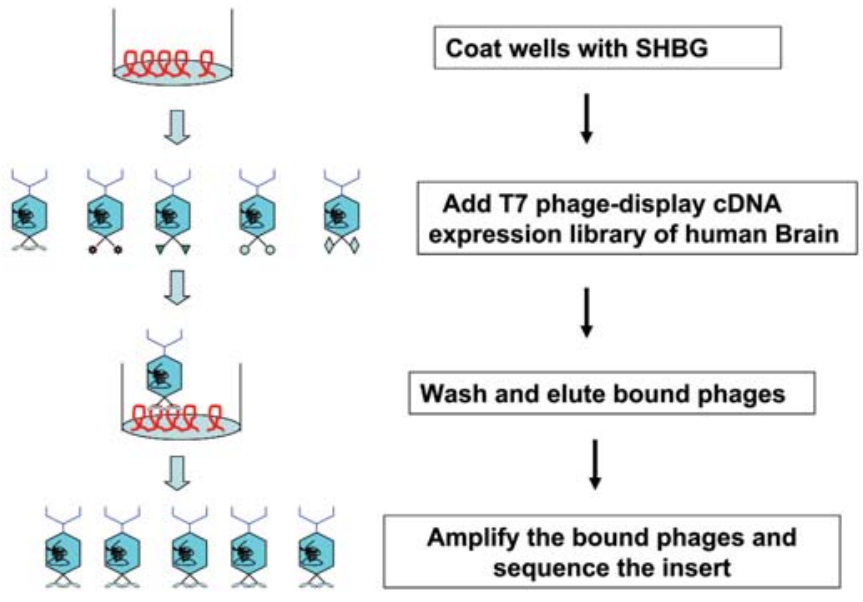

Figure 1. Schematic strategy to identify targets of SHBG.

in the choroids plexus, paraventricular and supraoptic nuclei, and in specific periventricular cells. Despite observations that suggest the presence of both central and peripheral SHBG membrane receptors, the identity of brain SHBG receptors has not been elucidated. Another study utilized a yeast two-hybrid system to identify candidate proteins for SHBG binding in prostate (27). In this study, phage display of a human brain cDNA library is used to identify SHBG-interacting proteins.

\section{Materials and methods}

Materials. The normal human brain T7Select ${ }^{\mathrm{TM}}$ phage library, host strain BLT5403, as well as primers were obtained from Novagen, USA. Qiaquick PCR purification kits were from Qiagen (Valencia, CA). Jumpstart TAQ polymerase was from Sigma (St. Louis, MO).

Biopanning. The strategy to identify the SHBG interacting proteins is presented in Fig. 1. Briefly, biopanning was performed as follows. SHBG was diluted in deionized water to $10 \mu \mathrm{g} / \mathrm{ml} ; 100 \mu \mathrm{l}$ aliquots were coated in the wells of a 96-well microtiter plate (Costar, Corning, NY) and incubated at room temperature (RT) for $3 \mathrm{~h}$. The SHBG-coated wells were then washed with Tris-buffered saline (TBS), blocked by adding $200 \mu 13 \%$ BSA to each well and incubated at RT for $1 \mathrm{~h}$. Excess blocking reagent was removed by washing with deionized water. The T7Select phage of the human normal brain cDNA library (Novagen, USA) was added to wells and incubated at RT for $1 \mathrm{~h}$. Unbound phages were washed off with TBS containing Tween while bound phages were then eluted by incubating each well with $200 \mu 1$ of $1 \%$ SDS in TBS. The eluted phages were then used to infect $E$. coli BLT5403 which amplifies the phages for the next biopanning cycle. Three more biopanning rounds were done to increase the phage binding affinity to the SHBG. Finally, the phages obtained after this fourth amplification were plaque titered with a series of dilutions $\left(10^{-2}\right.$ to $\left.10^{-14}\right)$ on LB agar plates containing $1 \%$ agarose and incubated for $2-4 \mathrm{~h}$ at $37^{\circ} \mathrm{C}$. Single plaques of phages were randomly selected with a pipette tip, resuspended in $100 \mu \mathrm{l}$ of $0.1 \mathrm{X}$ TE buffer, boiled for $10 \mathrm{~min}$ and placed on ice for $5 \mathrm{~min}$. To amplify the phage DNA, $1 \mu \mathrm{l}$

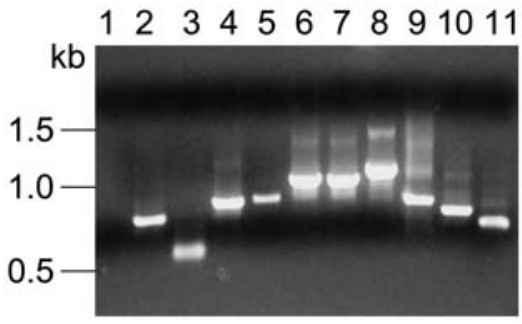

Figure 2. Size distribution of phage clones obtained from first round of biopanning. Phage bound to SHBG from the first cycle of biopanning were eluted and amplified on BLT5403. The amplified phages were plated with BLT5403 on LB agar plates for plaque formation. Ten plaques were randomly selected for PCR amplification. Amplified PCR products $(5 \mu 1)$ were loaded on $1 \%$ agarose gel containing Etbr and electrophoresed for $30 \mathrm{~min}$. The resolved gel was observed on a UV transilluminator and the image was captured using Kodak digital software. Lane 1, control PCR that lacks a template; lanes 2-11 random phage clones.

of the boiled samples were used as DNA templates for PCR amplification.

PCR and DNA sequencing. DNAs of the selected phage clones were amplified by PCR according to the manufacturer's (Novagen) instructions on a Perkin Elmer Thermocycler using the T7Select up 5'-GGAGCTGTCGTATTCCAGTC-3' and T7Select down 5'-GGCTGATACCACCCTTCAAG-3' as forward and reverse primers respectively. $\mathrm{PCR}$ conditions were 30 cycles of denaturation at $94^{\circ} \mathrm{C}$ for $30 \mathrm{sec}, 55^{\circ} \mathrm{C}$ annealing for $30 \mathrm{sec}$, and $72^{\circ} \mathrm{C}$ extension for $30 \mathrm{sec}$. A final extension at $72^{\circ} \mathrm{C}$ was for $5 \mathrm{~min}$. The reaction products were resolved on agarose gel to confirm the presence of amplification products. The PCR products were then purified using the Qiaquick PCR purification kit (Qiagen, Valencia, CA) and the inserts were sequenced on both strands at DNA Services Facility (Research Resources Center, University of Illinois at Chicago, IL) to confirm the authenticity of the genes. The determined DNA sequences were then analyzed by BLAST analyses.

\section{Results}

Over twenty phage clones bound to SHBG. Of these, initially we isolated ten phage plaques from the fourth round of biopanning and processed them for sequencing. Agarose gel resolution of the PCR products showed that they were all the same size (data not shown), so we sequenced two clones out of the ten. Sequence analysis demonstrated that SHBG-interacting phage clones encoded for FAU gene products [ubiquitin-like protein (FUBI) and ribosomal protein S30] (28).

Because of the low molecular weight of these two candidate proteins, we decided to screen more plaques from the first biopanning. Through this process we isolated twenty-four more phage clones. All these clones were then processed for sequencing. Fig. 2 shows the size distribution of the phage clones that were obtained after PCR amplification. The size of these clones varied between 570 and 1,265 bases. Each of the sequences was then subjected to a BLAST search to determine their identity. Table I shows the list of candidate proteins encoded by a phage that bound to SHBG. These 
Table I. Putative proteins that bind to SHBG by phage display technique.

\begin{tabular}{|c|c|}
\hline Phage clone no. & Encoding proteins \\
\hline \multicolumn{2}{|l|}{ Membrane } \\
\hline 1 & $\begin{array}{l}\text { Synaptosomal-associated protein } \\
(\text { SNAP } 25), 25 \mathrm{kDa}\end{array}$ \\
\hline 2 & $\begin{array}{l}\text { Thy-1 glycoprotein, Thy-1 cell } \\
\text { surface antigen }\end{array}$ \\
\hline 3 & Zonadhesin (ZAN) \\
\hline \multicolumn{2}{|c|}{$\begin{array}{l}\text { Dual localization: } \\
\text { Membrane and intracellular }\end{array}$} \\
\hline 4 & GTP-binding protein (RAB3A) \\
\hline 5 & Myelin basic protein \\
\hline 6 & Vacuolar protein sorting factor $4 \mathrm{~A}$ \\
\hline \multicolumn{2}{|l|}{ Intracellular } \\
\hline 7 & Adenylate kinase 5 \\
\hline 8 & $\begin{array}{l}\text { ADP-ribosylation factor } 6 \\
\text { interacting protein } 4 \text { (ARL61P4) }\end{array}$ \\
\hline 9 & Cystatin $\mathrm{C}$ \\
\hline 10 & $\begin{array}{l}\text { Cytoplasmic linker } 2 \text { (CYLN2), } \\
\text { variant } 2\end{array}$ \\
\hline 11 & Fatty acid binding protein 5 \\
\hline 12 & Fubi (also coded for by the FAU gene) \\
\hline 13 & FUS glycin rich protein \\
\hline 14 & Lymphoid-enhancer binding factor 1 \\
\hline 15 & Mitochondrial ribosomal protein S6 \\
\hline 16 & $\begin{array}{l}\text { Phospolipase A2, group IVC } \\
\text { (cytosolic calcium-independent) } \\
\text { (PLA2G4C) gene }\end{array}$ \\
\hline 17 & PR-domain zinc finger protein 2 variant \\
\hline 18 & Ribosmal protein L15 \\
\hline 19 & Ribosomal protein L10 \\
\hline 20 & Ribosomal protein L13 \\
\hline 21 & Ribosomal protein L17, transcript 1 \\
\hline 22 & Ribosomal protein S30 (FAU), \\
\hline 23 & $\begin{array}{l}\text { Transcription elongation factor A } \\
\text { (SII)-like } 3 \text { (TCEAL3) }\end{array}$ \\
\hline 24 & Zinc finger protein 260 \\
\hline
\end{tabular}

include cell membrane associated proteins (SNAP25, Thy-1 cell surface antigen, and zonadhesin), GTP-binding protein (RAB3A), myelin basic protein and vacuolar protein sorting factor $4 \mathrm{~A}$.

\section{Discussion}

SHBG is a $94-\mathrm{kDa}$ protein found in the blood $(10,29,30)$, brain (23-25), and the male reproductive tract $(24,31)$. One model of SHBG action suggests that it is a passive carrier of steroids in blood, while another model suggests that there are receptors for SHBG on cellular membranes that mediate intracellular actions $(1,5,21,22,32-34)$. In this study, we tested whether we could utilize the phage display technique to identify proteins that interact with SHBG. This technique identified over twenty binding proteins. Of these identified candidate proteins three are localized to the cell membrane [SNAP25 (35), Thy-1 cell surface antigen (36), and zonadhesin (37)]. Some of the other proteins include GTP-binding protein (RAB3A) (38), myelin basic protein (39) and vacuolar protein sorting factor 4A (40). These findings demonstrate that both cytoplasmic and membrane proteins interact with SHBG. The majority of the identified proteins are intracellular with a good number of them involved in protein synthesis.

Pope and Lee sequenced at least sixty proteins from over 230 interacting proteins they obtained using the yeast twohybrid system to identify prostatic SHBG binding proteins (27). Two of the metabolic cytosolic proteins we identified, Adenylate kinase 5 and Phospolipase A2, group IVC, were also identified by them (27). Adenylate kinase is involved in the homeostasis of adenine and guanine nucleotides (41), while phospholipase A2 catalyzes the hydrolysis of the 2-acyl bond of 3-n-phosphoglycerides (42). However, despite the high number of membrane proteins they obtained, none of them are high molecular weight proteins. Interestingly, adenylate kinase and phospholipase A2 were shown to be over-expressed in prostatic cancer $(43,44)$ and the putative SHBG receptor was also first described in the prostate (1). Given the association of these proteins with SHBG in the brain it is not known at this time if these proteins are also involved in brain cancer. If so, elucidation of the interaction of SHBG with these proteins may have implications for steroid-initiated tumorigenesis.

Because others have postulated that the SHBG receptor is associated with the cellular membrane, we will first discuss candidate proteins associated with the cellular membrane. Of the three membrane-associated candidate proteins, only zonadhesin has a molecular weight that corresponds to the molecular weight suggested by Hryb et al (1) for the putative SHBG receptor, i.e. $167 \mathrm{kDa}$. It is known that zonadhesin forms two disulfide-bonded monomeric constituents of 105 and $45 \mathrm{kDa}$, for a total molecular weight of $150 \mathrm{kDa}$. Zonadhesin is a mosaic protein in sperm membrane fractions that binds directly and in a species-specific manner to the extracellular matrix (zona pellucida; ZP) of the oocytes. Posttranslational processing leads to multiple forms of zonadhesin with differing apparent avidities for the ZP (45). In the pig, the p105/45 form binds preferentially to conspecific ZP (45). It is interesting that with the discovery of membrane receptors for progesterone in oocytes (46-48), that rapid steroid effects in oocytes are receiving renewed interest. We found SHBG immunoreactivity in prostatic secretions (24), which suggests that SHBG in the ejaculate serves as a stimulatory agent at oocyte membrane receptors, as with zonadhesin. However, it is not known whether zonadhesin exists in the brain. Using Northern blot analysis, zonadhesin expression was found only within the testes and it was not detected in other organs including the brains of mice (49). However, due to the presence of MAM, mucin, D-, and EGF domains in zonadhesin, Gao and Garbers (49) suggested that apart from binding to zona pellucida, mouse zonadhesin functions in other cell adhesion processes. Our suggestion that zonadhesin exists in the human brain might indicate its involvement in cell adhesion and possibly cell migration during development. 
Another indicator that a candidate protein is associated with the membrane is coupling to $G$ proteins. We identified RAB3A as a candidate protein, which is a GTP-binding protein of $24 \mathrm{kDa}$ which belongs to the GTP-binding protein superfamily. RAB3A and its interacting proteins are involved in $\mathrm{Ca}^{2+}$-dependent exocytosis (50). RAB3A has been identified in membrane and cytosolic fractions of mouse with the predominant form being membrane-bound. The localization to acrosomal membrane suggests a role for RAB3A in the regulation of zona pellucida-induced acrosomal exocytosis (51) that, along with identification of zonadhesin, may indicate a parallel receptor complex in brain and acrosome.

Soluble N-ethylmaleimide-sensitive factor attachment protein (SNAP-25) is an integral membrane protein localized to the plasma membrane of pre-synaptic axon terminals. As a component of the SNARE (receptor for SNAPs), SNAP-25 appears to play an important role in the docking and fusion of pre-synaptic vesicles during exocytosis of neurotransmitters (52). Pope and Lee (27) identified another protein called SNARE associated protein which is also a component of the SNARE complex (53). SHBG internalization was observed in a number of tissues $(7,8,10,11,13,54)$ including the brain $(15)$, so it is possible that some of the proteins we identified here, in particular SNAP-25, are involved in that internalization process.

We also discovered that one protein binding to SHBG is myelin basic protein. Myelin basic protein (MBP) makes up $\sim 30 \%$ of the components of a myelin sheath which electrically insulates axons and aids conduction of nerve impulses. There is significant interest in MBP because of its role in demyelinating diseases, particularly multiple sclerosis (MS). Several studies have shown a role for antibodies against MBP in the pathogenesis of MS (55). It is possible that one function of SHBG in the brain is due to actions at the level of myelin in brain fiber tracts. SHBG internalization was often associated with such tracts in the brain (15). It is also interesting to note that MBP is present in various different cell types including lymphoid cells and all types of myeloid lineage cells (i.e., macrophages, dendritic cells, granulocytes, megakaryocytes, and erythroblasts) (56). At least five isoforms of MBP were identified with molecular weights ranging from 14 to $21 \mathrm{kDa}$. (57). Again, this is not likely the SHBG receptor, but it could be a component of it. It was demonstrated that supplemental estrogen enhances the efficacy of TCR-based immunotherapy for autoimmune diseases that are predominant in females (58). Estrogen potentiates treatment with T-cell-receptor protein of female mice with experimental encephalomyelitis (EAE). This is a significant finding because the involvement of estrogen in the therapy of EAE (a mouse model for MS) also suggests a role for SHBG in its transportation and hence potential therapy for MS.

Thy-1 glycoproteins were identified as candidate proteins as well. Thy- 1 glycoproteins are constituents of thymocytes and neurons. Thy- 1 cell surface antigen is a small protein $(18 \mathrm{kDa})$ that may play a role in cell-cell or -ligand interactions during synaptogenesis and other events in the brain (UniProtKB/ Swiss-Prot, Institute of Bioinformatics and the EMBL outstationthe European Bioinformatics Institute). It was also shown that despite the fact that Thy-1 glycoprotein is anchored (glycosylphosphatidal-insoitol anchor) to the outer hemi-leaflet of the cell membrane, it is capable of transducing signals across the plasma membrane of murine T-lymphoma cells (59). To our knowledge, no such activity has been demonstrated in brain cells. In any case, the low molecular weight of Thy-1 suggests that it could only be part of a large receptor complex for SHBG.

Another candidate protein was vacuolar protein sorting factor 4A (VPS4), which is a member of the ATPases Associated with diverse cellular Activities (AAA) ATPase family and a central regulator for early endosome trafficking (60). This protein is well characterized in yeast where it is known to bind to oxysterol binding protein and regulate intracellular lipid and vesicular transport (25). Since VPS4 has a molecular weight of $48 \mathrm{kDa}(61)$, it is not likely to be the anticipated SHBG receptor, however it could be one of the components of the receptor, which after being internalized, functions in the transport of SHBG-bound steroid.

Although FUBI and ribosomal protein S30 are cytosolic low molecular weight proteins, they were obtained at the fourth panning suggesting that they had the highest affinity for SHBG. FUBI is synthesized with ribosomal S30 as its Cterminal extension. It was proposed that the fusion protein is post-translationally processed to generate free FUBI and free ribosomal protein $\mathrm{S} 30$. FUBI is a member of the ubiquitin family, and ribosomal protein S30 belongs to the S30E family of ribosomal proteins. Whereas the function of FUBI is currently unknown, ribosomal protein $\mathrm{S} 30$ is a component of the $40 \mathrm{~S}$ subunit of the cytoplasmic ribosome (62). It is also interesting to note the high number of other ribosomal proteins that are involved in binding to SHBG. It is not known what the consequences of the interaction of SHBG with FUBI or ribosomal proteins are or any possible involvement in steroid metabolism. However, it will be interesting to investigate, using cell culture systems, how these proteins are modified in the presence of SHBG and how their deficiencies affect steroid metabolism.

This phage display system did not identify megalin which is a candidate for the SHBG receptor as mentioned above. The failure of SHBG to identify megalin may be due to the inability of phages to fuse large proteins or simply that megalin is absent in the brain.

Overall, it seems likely that the SHBG receptor is made up of several protein subunits and that any one of the proteins we identified could be a component of the large molecule. For example, there are four proteins in the presynaptic terminal involved in neurotransmitter release, RAB3A, SNAP-25, VAMP/synaptobrevin-2 and syntaxin, all form a complex of $\sim 119 \mathrm{kDa}$ (63). Another study that lends credibility to this argument is by Oike et al (64) who showed that Group IIA phospholipase A2 is coexpressed with SNAP-25 in rat mature taste receptor cells that possess exocytotic function. If several elements of the SHBG receptor complex are only transiently found in the membrane, it may explain why Pope and Lee (27) were unable to identify a single protein of high molecular weight using their yeast two-hybrid method.

Because the phages of the Phage Display technique display all proteins on their surface, it may be that we here demonstrated SHBG binding to proteins that are normally only able to interact with SHBG within the cell. SHBG internalization has been demonstrated in multiple tissues $(7-9,11-13,54)$ including the brain (15) suggesting that SHBG along with associated 
steroids are selectively brought into cells, where cytosolic proteins may bind the SHBG. This work may have identified proteins that are candidates for an intracellular SHBGbinding complex.

\section{Acknowledgements}

This work was completed with funding from R21-MH069810 (JDC) and Excellence in Academic Medicine grant of the Swedish American Health System (MG).

\section{References}

1. Hryb DJ, Khan MS, Romas NA and Rosner W: Solubilization and partial characterization of the sex hormone-binding globulin receptor from human prostate. J Biol Chem 264: 5378-5383, 1989.

2. Nakhla AM, Khan MS, Romas NP and Rosner W: Estradiol causes the rapid accumulation of cAMP in human prostate. Proc Natl Acad Sci USA 91: 5402-5405, 1994.

3. Nakhla AM, Leonard J, Hryb DJ and Rosner W: Sex hormonebinding globulin receptor signal transduction proceeds via a $G$ protein. Steroids 64: 213-216, 1999.

4. Rosner W, Hryb DJ, Khan MS, Nakhla AM and Romas NA: Androgen and estrogen signaling at the cell membrane via Gproteins and cyclic adenosine monophosphate. Steroids 64 100-106, 1999

5. Avvakumov GV, Zhuk NI and Strel'chyonok OA: Subcellular distribution and selectivity of the protein-binding component of the recognition system for sex-hormone-binding protein-estradiol complex in human decidual endometrium. Biochim Biophys Acta 881: 489-498, 1986.

6. Strel'chyonok OA, Avvakumov GV and Survilo LI: A recognition system for sex-hormone-binding protein-estradiol complex in human decidual endometrium plasma membranes. Biochim Biophys Acta 802: 459-466, 1984

7. Gerard A: Endocytosis of androgen-binding protein (ABP) by spermatogenic cells. J Steroid Biochem Mol Biol 53: 533-542, 1995.

8. Gueant JL, Fremont S, Felden F, Nicolas JP, Gerard A, Leheup B, Gerard $\mathrm{H}$ and Grignon $\mathrm{G}$ : Evidence that androgen-binding protein endocytosis in vitro is receptor mediated in principal cells of the rat epididymis. J Mol Endocrinol 7: 113-122, 1991.

9. Meyer S, Brumm C, Stegner HE and Sinnecker GH: Intracellular sex hormone-binding globulin (SHBG) in normal and neoplastic breast tissue--an additional marker for hormone dependency? Exp Clin Endocrinol 102: 334-340, 1994.

10. Pardridge WM: Transport of protein-bound hormones into tissues in vivo. Endocr Rev 2: 103-123, 1981

11. Porto CS, Gunsalus GL, Bardin CW, Phillips DM and Musto NA Receptor-mediated endocytosis of an extracellular steroid-binding protein (TeBG) in MCF-7 human breast cancer cells. Endocrinology 129: 436-445, 1991 .

12. Porto CS, Lazari MF, Abreu LC, Bardin CW and Gunsalus GL: Receptors for androgen-binding proteins: internalization and intracellular signalling. J Steroid Biochem Mol Biol 53: 561-565, 1995

13. Sakiyama R, Pardridge WM and Musto NA: Influx of testosteronebinding globulin (TeBG) and TeBG-bound sex steroid hormones into rat testis and prostate. J Clin Endocrinol Metab 67: 98-103, 1988.

14. Sinnecker G, Hiort O, Kwan PW and DeLellis RA: Immunohistochemical localization of sex hormone-binding globulin in normal and neoplastic breast tissue. Horm Metab Res 22: 47-50, 1990.

15. Caldwell JD, Shapiro RA, Jirikowski GF and Suleman F: Internalization of sex hormone-binding globulin into neurons and brain cells in vitro and in vivo. Neuroendocrinology 86: 84-93, 2007.

16. Hammes A, Andreassen TK, Spoelgen R, Raila J, Hubner N, Schulz H, Metzger J, Schweigert FJ, Luppa PB, Nykjaer A and Willnow TE: Role of endocytosis in cellular uptake of sex steroids. Cell 122: 751-762, 2005.

17. Willnow TE, Nykjaer A and Herz J: Lipoprotein receptors: new roles for ancient proteins. Nat Cell Biol 1: E157-E162, 1999

18. Mopert B, Herbert Z, Caldwell JD and Jirikowski GF: Expression of corticosterone-binding globulin in the rat hypothalamus. Horm Metab Res 38: 246-252, 2006.
19. Sivukhina EV, Jirikowski GF, Bernstein HG, Lewis JG and Herbert Z: Expression of corticosteroid-binding protein in the human hypothalamus, co-localization with oxytocin and vasopressin. Horm Metab Res 38: 253-259, 2006.

20. Petersen HH, Andreassen TK, Breiderhoff T, Brasen JH, Schulz H, Gross V, Grone HJ, Nykjaer A and Willnow TE: Hyporesponsiveness to glucocorticoids in mice genetically deficient for the corticosteroid binding globulin. Mol Cell Biol 26: 7236-7245, 2006.

21. Caldwell JD, Moe BD, Hoang J and Nguyen T: Sex hormone binding globulin stimulates female sexual receptivity. Brain Res 874: 24-29, 2000

22. Caldwell JD, Hofle S and Englof I: Sex hormone binding globulin facilitates female sexual receptivity except when coupled to dihydrotestosterone. Brain Res 948: 102-107, 2002.

23. Herbert Z, Jirikowski GF, Petrusz P, Englof I and Caldwell JD: Distribution of androgen-binding protein in the rat hypothalamoneurohypophyseal system, co-localization with oxytocin. Brain Res 992: 151-158, 2003.

24. Herbert Z, Weigel S, Sendemir E, Marshall A, Caldwell JD, Petrusz P, Peuckert C and Jirikowski GF: Androgen-binding protein is co-expressed with oxytocin in the male reproductive tract. Anat Histol Embryol 34: 286-293, 2005.

25. Wang YM, Bayliss DA, Millhorn DE, Petrusz P and Joseph DR The androgen-binding protein gene is expressed in male and female rat brain. Endocrinology 127: 3124-3130, 1990.

26. Caldwell JD: Evidence of sex hormone binding globulin binding sites in the medial preoptic area and hypothalamus. Horm Metab Res 33: 7-9, 2001.

27. Pope SN and Lee IR: Yeast two-hybrid identification of prostatic proteins interacting with human sex hormone-binding globulin. J Steroid Biochem Mol Biol 94: 203-208, 2005.

28. Rossman TG, Visalli MA and Komissarova EV: fau and its ubiquitinlike domain (FUBI) transforms human osteogenic sarcoma (HOS) cells to anchorage-independence. Oncogene 22: 18171821,2003

29. Siiteri PK, Murai JT, Hammond GL, Nisker JA, Raymoure WJ and Kuhn RW: The serum transport of steroid hormones. Recent Prog Horm Res 38: 457-510, 1982.

30. Walsh KA, Titani K, Takio K, Kumar S, Hayes R and Petra PH Amino acid sequence of the sex steroid binding protein of human blood plasma. Biochemistry 25: 7584-7590, 1986

31. Hryb DJ, Nakhla AM, Kahn SM, St George J, Levy NC, Romas NA and Rosner W: Sex hormone-binding globulin in the human prostate is locally synthesized and may act as an autocrine/ paracrine effector. J Biol Chem 277: 26618-26622, 2002

32. Hryb DJ, Khan MS, Romas NA and Rosner W: The control of the interaction of sex hormone-binding globulin with its receptor by steroid hormones. J Biol Chem 265: 6048-6054, 1990

33. Khan MS, Hryb DJ, Hashim GA, Romas NA and Rosner W: Delineation and synthesis of the membrane receptor-binding domain of sex hormone-binding globulin. J Biol Chem 265: 18362-18365, 1990.

34. Krupenko NI, Avvakumov GV and Strel'chyonok OA: Binding of human sex hormone-binding globulin-androgen complexes to the placental syncytiotrophoblast membrane. Biochem Biophys Res Commun 171: 1279-1283, 1990.

35. Oyler GA, Polli JW, Wilson MC and Billingsley ML: Developmental expression of the $25-\mathrm{kDa}$ synaptosomal-associated protein (SNAP-25) in rat brain. Proc Natl Acad Sci USA 88: 5247-5251, 1991.

36. De Hoop MJ and Dotti CG: Membrane traffic in polarized neurons in culture. J Cell Sci (Suppl) 17: 85-92, 1993

37. Hardy DM and Garbers DL: A sperm membrane protein that binds in a species-specific manner to the egg extracellular matrix is homologous to von Willebrand factor. J Biol Chem 270: 26025-26028, 1995.

38. Fischer von Mollard G, Sudhof TC and Jahn R: A small GTPbinding protein dissociates from synaptic vesicles during exocytosis. Nature 349: 79-81, 1991.

39. Gillespie CS, Wilson R, Davidson A and Brophy PJ: Characterization of a cytoskeletal matrix associated with myelin from rat brain. Biochem J 260: 689-696, 1989.

40. Beyer A, Scheuring S, Muller S, Mincheva A, Lichter P and Kohrer K: Comparative sequence and expression analyses of four mammalian VPS4 genes. Gene 305: 47-59, 2003.

41. Yoneda T, Sato M, Maeda M and Takagi H: Identification of a novel adenylate kinase system in the brain: cloning of the fourth adenylate kinase. Brain Res Mol Brain Res 62: 187-195, 1998.

42. Dennis EA: Diversity of group types, regulation, and function of phospholipase A2. J Biol Chem 269: 13057-13060, 1994. 
43. Hall M, Mickey DD, Wenger AS and Silverman LM: Adenylate kinase: an onco-developmental marker in an animal model for human prostatic cancer. Clin Chem 31: 1689-1691, 1985.

44. Sved P, Scott KF, McLeod D, King NJ, Singh J, Tsatralis T, Nikolov B, Boulas J, Nallan L, Gelb MH, Sajinovic M, Graham GG, Russell PJ and Dong Q: Oncogenic action of secreted phospholipase A2 in prostate cancer. Cancer Res 64: 6934-6940, 2004.

45. Hickox JR, Bi M and Hardy DM: Heterogeneous processing and zona pellucida binding activity of pig zonadhesin. J Biol Chem 276: 41502-41509, 2001

46. King Wt, Ghosh S, Thomas P and Sullivan CV: A receptor for the oocyte maturation-inducing hormone 17alpha,20beta,21trihydroxy-4-pregnen-3-one on ovarian membranes of striped bass. Biol Reprod 56: 266-271, 1997.

47. Thomas P, Zhu Y and Pace M: Progestin membrane receptors involved in the meiotic maturation of teleost oocytes: a review with some new findings. Steroids 67: 511-517, 2002.

48. Zhu Y, Rice CD, Pang Y, Pace M and Thomas P: Cloning, expression, and characterization of a membrane progestin receptor and evidence it is an intermediary in meiotic maturation of fish oocytes. Proc Natl Acad Sci USA 100: 2231-2236, 2003.

49. Gao Z and Garbers DL: Species diversity in the structure of zonadhesin, a sperm-specific membrane protein containing multiple cell adhesion molecule-like domains. J Biol Chem 273: 3415-3421, 1998.

50. Takai Y, Sasaki T, Shirataki H and Nakanishi H: Rab3A small GTP-binding protein in $\mathrm{Ca}(2+)$-dependent exocytosis. Genes Cells 1: 615-632, 1996.

51. Ward CR, Faundes D and Foster JA: The monomeric GTP binding protein, rab3a, is associated with the acrosome in mouse sperm. Mol Reprod Dev 53: 413-421, 1999.

52. Goda Y: SNAREs and regulated vesicle exocytosis. Proc Natl Acad Sci USA 94: 769-772, 1997.

53. Ilardi JM, Mochida S and Sheng ZH: Snapin: a SNAREassociated protein implicated in synaptic transmission. Nat Neurosci 2: 119-124, 1999.

54. Bordin S and Petra PH: Immunocytochemical localization of the sex steroid-binding protein of plasma in tissues of the adult monkey Macaca nemestrina. Proc Natl Acad Sci USA 77: 5678-5682, 1980.
55. Berger T, Rubner P, Schautzer F, Egg R, Ulmer H, Mayringer I, Dilitz E, Deisenhammer F and Reindl M: Antimyelin antibodies as a predictor of clinically definite multiple sclerosis after a first demyelinating event. N Engl J Med 349: 139-145, 2003.

56. Kim JG, Nonneman D, Vallet JL, Rohrer GA and Christenson RK: Linkage mapping of the porcine myelin basic protein gene to chromosome 1. Anim Genet 36: 163-164, 2005.

57. Mathisen PM, Pease S, Garvey J, Hood L and Readhead C: Identification of an embryonic isoform of myelin basic protein that is expressed widely in the mouse embryo. Proc Natl Acad Sci USA 90: 10125-10129, 1993.

58. Offner H, Adlard K, Zamora A and Vandenbark AA: Estrogen potentiates treatment with $\mathrm{T}$-cell receptor protein of female mice with experimental encephalomyelitis. J Clin Invest 105: $1465-1472,2000$

59. Lemansky P, Fatemi SH, Gorican B, Meyale S, Rossero R and Tartakoff AM: Dynamics and longevity of the glycolipid-anchored membrane protein, Thy-1. J Cell Biol 110: 1525-1531, 1990.

60. Scheuring S, Rohricht RA, Schoning-Burkhardt B, Beyer A, Muller S, Abts HF and Kohrer K: Mammalian cells express two VPS4 proteins both of which are involved in intracellular protein trafficking. J Mol Biol 312: 469-480, 2001.

61. Babst M, Sato TK, Banta LM and Emr SD: Endosomal transport function in yeast requires a novel AAA-type ATPase, Vps4p. EMBO J 16: 1820-1831, 1997.

62. Kas K, Michiels L and Merregaert J: Genomic structure and expression of the human fau gene: encoding the ribosomal protein S30 fused to a ubiquitin-like protein. Biochem Biophys Res Commun 187: 927-933, 1992.

63. Horikawa HP, Saisu H, Ishizuka T, Sekine Y, Tsugita A, Odani S and Abe T: A complex of rab3A, SNAP-25, VAMP/synaptobrevin-2 and syntaxins in brain presynaptic terminals. FEBS Lett 330: 236-240, 1993.

64. Oike H, Matsumoto I and Abe K: Group IIA phospholipase $\mathrm{A}(2)$ is coexpressed with SNAP-25 in mature taste receptor cells of rat circumvallate papillae. J Comp Neurol 494: 876-886, 2006. 